\title{
Inhibition of reproduction in rams by long daylengths and the acute effect of superior cervical ganglionectomy
}

\author{
G. A. Lincoln and O. F. X. Almeida \\ M.R.C. Reproductive Biology Unit, Centre for Reproductive Biology, 37 Chalmers Street, \\ Edinburgh EH3 $9 E W, U . K$.
}

\begin{abstract}
Summary. Six castrated Soay rams were given testosterone implants, and exposed to an artificial lighting regimen of alternating 16 -week periods of long days (16L:8D) and short days (8L:16D) for over 1 year. Under these conditions, the blood plasma concentration of testosterone was maintained relatively constant $(4 \cdot 3-6.4 \mathrm{ng} / \mathrm{ml})$, while the levels of $\mathrm{LH}$ and prolactin varied in relation to the alterations in the photoperiod; low levels of LH occurred during long days when the rams were hyperprolactinaemic. During the last period of exposure to long days, 4 of the rams were cranially sympathectomized by removing the superior cervical ganglia. The effect of long daylengths on the secretion of $\mathrm{LH}$ and prolactin was blocked; prolactin concentrations began to decline after 2 weeks and LH levels increased. Ganglionectomy also influenced the plasma levels of melatonin; after the operation there was no longer a consistent $24-\mathrm{h}$ rhythm in melatonin values and the increase associated with darkness was abolished. This result supports the view that the regulation of melatonin secretion is involved in the photoperiodic control of reproduction in rams.
\end{abstract}

\section{Introduction}

Exposure of rams to long daylengths after short daylengths results in a decline in the secretion of luteinizing hormone (LH) and regression of the testes (Pelletier \& Ortavant, 1975; Lincoln \& Short, 1980). This photoperiodic response is blocked or modified if the animals are pinealectomized (Barrell \& Lapwood, 1979a, b) or the superior cervical ganglia are removed (Lincoln, 1979). Both of these operations interfere with the normal function of the pineal gland and there is evidence that the daily rhythm in the secretion of melatonin by the pineal gland is involved in the way photoperiod influences reproduction (Rollag, O'Callaghan $\&$ Niswender, 1978; Kennaway, Porter \& Seamark, 1978; Arendt, Forbes, Brown \& Marston, 1980; Lincoln, Almeida \& Arendt, 1981).

To investigate the mechanism of the photoperiodic response we have now studied the acute effects of superior cervical ganglionectomy on the hourly fluctuations in the blood levels of melatonin, prolactin and $\mathrm{LH}$ in Soay rams exposed to alternating periods of long days and short days. To provide a simplified model we have used castrated Soay rams in which a constant circulating level of testosterone was maintained by an implant of testosterone.

\section{Materials and Methods}

Animals and operations. Six adult rams of the Soay breed of semi-domesticated sheep were housed in a light-proof building, and exposed to an artificial lighting regimen of alternating 16-week periods of long days (16 h light: $8 \mathrm{~h}$ darkness, $16 \mathrm{~L}: 8 \mathrm{D})$ and short days $(8 \mathrm{~L}: 16 \mathrm{D})$ as described previously (Lincoln \& Short, 1980). 
Before the start of the present study all rams were castrated surgically by removal of the testes and epididymides. Subsequently, each ram was implanted subcutaneously on the flank with a Silastic envelope containing crystalline testosterone. Both operations were performed under fluothane anaesthesia. The implants had a surface area of approximately $40 \mathrm{~cm}^{2}$ and were made from Silastic sheeting (500-1: Dow Corning, Midland, Michigan, U.S.A.) formed into an envelope containing $5.0 \mathrm{~g}$ testosterone (Sigma Chemicals, Poole, Dorset, U.K.) and sealed with an appropriate adhesive.

Towards the end of the study, during a period of long days (Day 88 since the change from short days to long days), 4 of the rams were cranially sympathectomized by removal of the superior cervical ganglion from both sides of the neck (Appleton \& Waites, 1955). The remaining 2 rams acted as controls and received a sham operation. All the operations were completed within 2 days. The individual animals were anaesthetized while in the home pen using fluothane anaesthetic inhaled through a mask. They were then transported to the surgery where the anaesthesia was maintained using a mixture of fluothane, nitrous oxide and oxygen. Each operation took approximately $2 \mathrm{~h}$. The rams were given a 6-day post-operative course of the antibiotic Streptopen (Glaxo, England) and made uneventful recoveries.

Assays. Twice weekly blood samples were collected from the jugular vein of each ram for 44 weeks before and 10 weeks after the ganglionectomy or sham operations. Blood samples were also collected at hourly intervals for $75 \mathrm{~h}$ during the operations, and for $30 \mathrm{~h} 42$ days later. To permit this frequent sampling each ram was fitted with a cannula inserted into the jugular vein on the day before samples were collected. The cannulae were kept patent using heparinized saline. All blood samples were centrifuged within $30 \mathrm{~min}$ of collection and the plasma was frozen at $-20^{\circ} \mathrm{C}$ until required for hormone assay.

The concentrations of melatonin, prolactin, $\mathrm{LH}$ and testosterone in the blood plasma were measured by radioimmunoassays. Details of the methods and validation for use with sheep plasma are described elsewhere for melatonin (Rollag \& Niswender, 1976), prolactin (McNeilly \& Andrews, 1974), LH (Scaramuzzi, Caldwell \& Moor, 1970), and testosterone (Corker \& Davidson, 1978). The reference standard for LH was NIH-LH-S14 and that for prolactin was NIH-P-S9. The lower limits of detection for the various assays were as follows: $15 \mathrm{pg}$ melatonin $/ \mathrm{ml} ; 5 \mathrm{ng}$ prolactin $/ \mathrm{ml} ; 0.25 \mathrm{ng} \mathrm{LH} / \mathrm{ml}$ and $0.1 \mathrm{ng}$ testosterone $/ \mathrm{ml}$. All the samples from a single animal were assayed in duplicate in the same assay and the intra-assay coefficient of variation was $<15 \%$ for all the assays.

Analysis. A consistency test was used in the analysis of the daily hormone profiles to indicate periods when the plasma levels were consistently high or low. This involved calculating the 24-h median hormone value for each individual animal, and then determining the hourly values which were above or below the median. The periods when at least 4 consecutive hourly values were of the same sign were taken as the times when hormone levels were consistently high or low (see Text-fig. 3).

\section{Results}

\section{Effect of photoperiod}

The changes in the concentration of $\mathrm{LH}$, prolactin and testosterone in the blood plasma of the rams during the first 44 weeks of study are summarized in Text-fig. 1. The levels of testosterone were relatively constant for each individual animal (overall mean \pm s.e.m., $4 \cdot 3 \pm$ $0.2-6.4 \pm 0.2 \mathrm{ng} / \mathrm{ml}$ ), indicating a steady release of the hormone into the circulation from the implants. The levels of $\mathrm{LH}$ and prolactin changed markedly during the study and were correlated with the alterations in the photoperiod. During long days the mean concentration of $\mathrm{LH}$ decreased in all animals from $>18.0$ to $<2.0 \mathrm{ng} / \mathrm{ml}$, while after transfer back to short days the values gradually increased again. There was an inverse relationship between the changes in the levels of $\mathrm{LH}$ and those of prolactin which were at a maximum during long days when LH levels were suppressed (Text-fig. 1). 


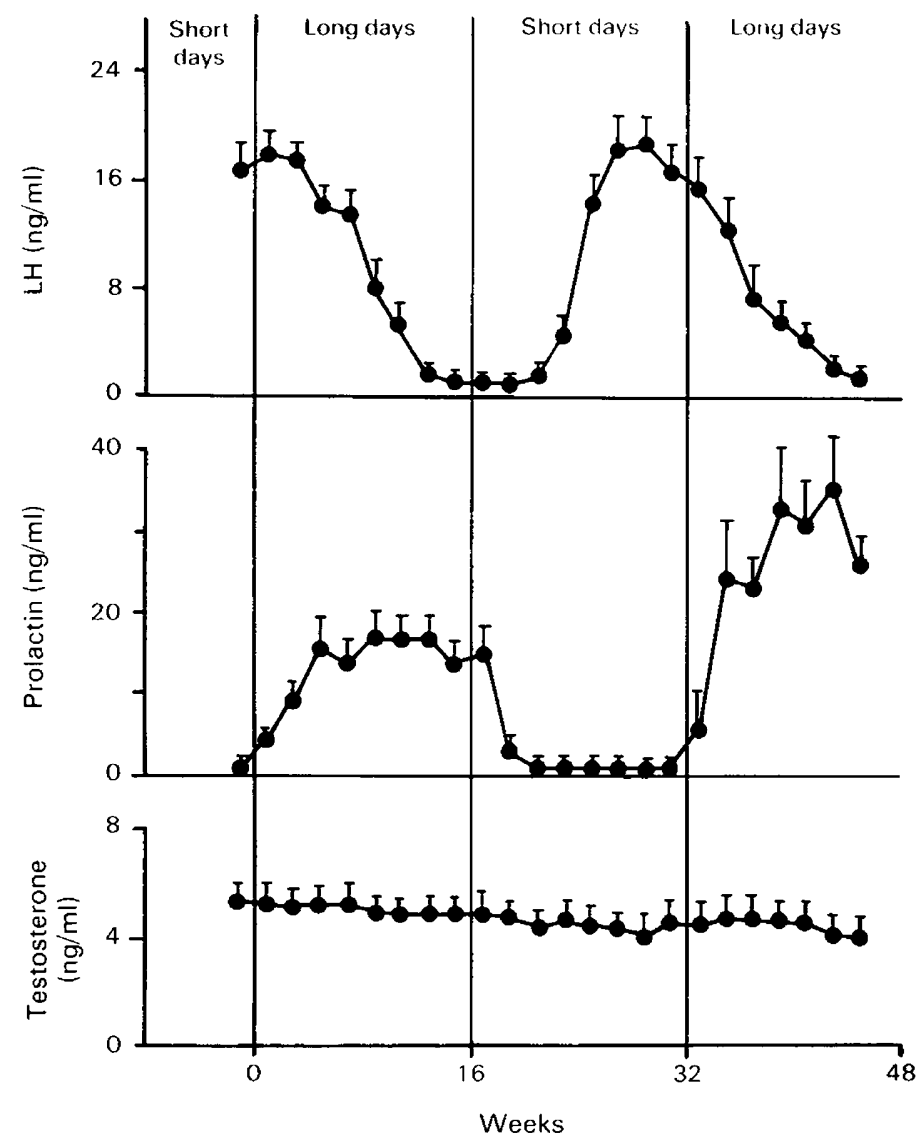

Text-fig. 1. Changes in the concentrations of $\mathrm{LH}$, prolactin and testosterone (2-weekly mean \pm s.e.m.) in the blood plasma of 6 adult Soay rams during exposure to alternating 16-week periods of short days (8L:16D) and long days (16L:8D) based on blood samples collected 1-2 times each week. The rams were castrated and given testosterone implants.

\section{Effect of superior cervical ganglionectomy}

As shown in Text-fig. 2, in all 4 ganglionectomized rams there was an increase in the concentration of LH in the plasma and a decrease in the concentration of prolactin. This change was evident within 23-36 days after the operation for LH and within 14-27 days for prolactin. In the 2 sham-operated animals plasma concentrations of $\mathrm{LH}$ were low and of prolactin were high throughout this period of exposure to long days.

More frequent blood sampling showed (Text-fig. 3) that at the time of surgery there was a transitory increase in the plasma levels of $\mathrm{LH}$, prolactin and melatonin in the ganglionectomized and sham-operated animals, suggesting that this was an initial effect of the operation procedures which was not specifically due to the removal of the superior cervical ganglia. Obvious differences between the ganglionectomized rams and the controls were evident by Day 45 (Text-fig. 3). The plasma levels of LH in the ganglionectomized rams were increased to a $24 \mathrm{~h}$ mean concentration of $4.19 \mathrm{ng} / \mathrm{ml}$ (range $1.00-9.14 \mathrm{ng} / \mathrm{ml}$ ) compared to only $0.37 \mathrm{ng} / \mathrm{ml}$ (range $0.26-0.47 \mathrm{ng} / \mathrm{ml}$ ) in the controls. This change was associated with an increase in the frequency of episodic peaks of LH with up to 8 peaks per $24 \mathrm{~h}$ in the ganglionectomized rams on Day 42 compared to none in the controls. The plasma levels of prolactin were markedly decreased in the ganglionectomized rams; by Day 45 the 24 -h mean concentration of prolactin 

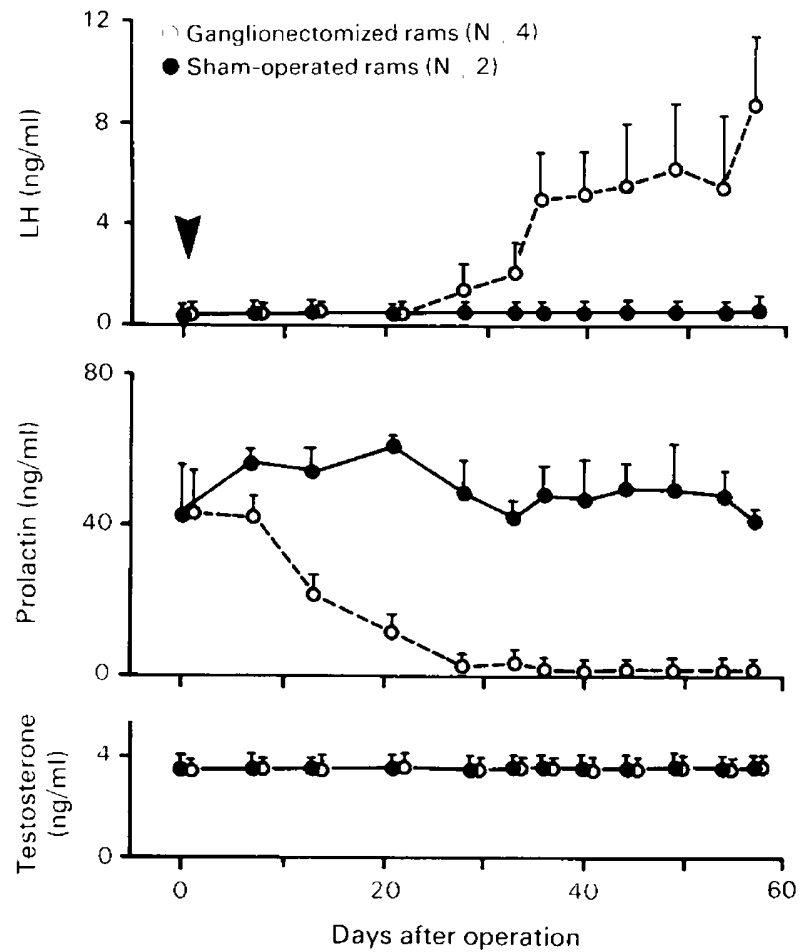

Text-fig. 2. Changes in the concentrations of $L H$, prolactin and testosterone in the blood plasma from adult Soay rams exposed to long days (16L:8D) after removal of the superior cervical ganglia (arrow, Week 48 in Text-fig. 1) or a sham operation. Values are mean \pm s.e.m. for ganglionectomized rams and mean and range for sham-operated rams.

was $6.0 \mathrm{ng} / \mathrm{ml}$ (range $3.0-10.0 \mathrm{ng} / \mathrm{ml}$ ) compared to $44.0 \mathrm{ng} / \mathrm{ml}$ (range $37.0-51.0 \mathrm{ng} / \mathrm{ml}$ ) for the controls. There was no obvious effect of ganglionectomy on the overall levels of melatonin in the blood plasma; the 24-h mean concentration of melatonin was $239 \mathrm{pg} / \mathrm{ml}$ (range 124-498 $\mathrm{pg} / \mathrm{ml}$ ) for the ganglionectomized rams compared to $253 \mathrm{pg} / \mathrm{ml}$ (range $93-412 \mathrm{pg} / \mathrm{ml}$ ) for the controls on Day 45. There was a change, however, in the plasma concentrations of melatonin related to the time of day. On the day before the operations there was an increase in the levels of melatonin in all animals associated with the daily period of $8 \mathrm{~h}$ darkness. This nocturnal peak was still obvious in the values for the 2 control rams immediately after the sham operation and on Day 45 (Text-fig. 3a). However, the hormone profiles for the 4 ganglionectomized rams showed no consistent increase in the levels of melatonin related to darkness once the superior cervical ganglia had been removed (Text-fig. 3b).

\section{Discussion}

In mammals, the pineal gland is thought to be involved in the mechanism by which photoperiod influences reproduction. The pineal is innervated by sympathetic nerves arriving by way of the superior cervical ganglia, and any procedure which interrupts this nerve supply disrupts the normal secretory activity of the gland (Moore, 1978). Studies on a variety of seasonally breeding animals, including the sheep, have shown that pinealectomy and superior cervical ganglionectomy produce similar disruptive effects on the photoperiodic control of reproduction (e.g. sheep: Barrell \& Lapwwod, 1979a, b; horse: Sharp, Vernon \& Zavy, 1979; golden hamster: Reiter, 

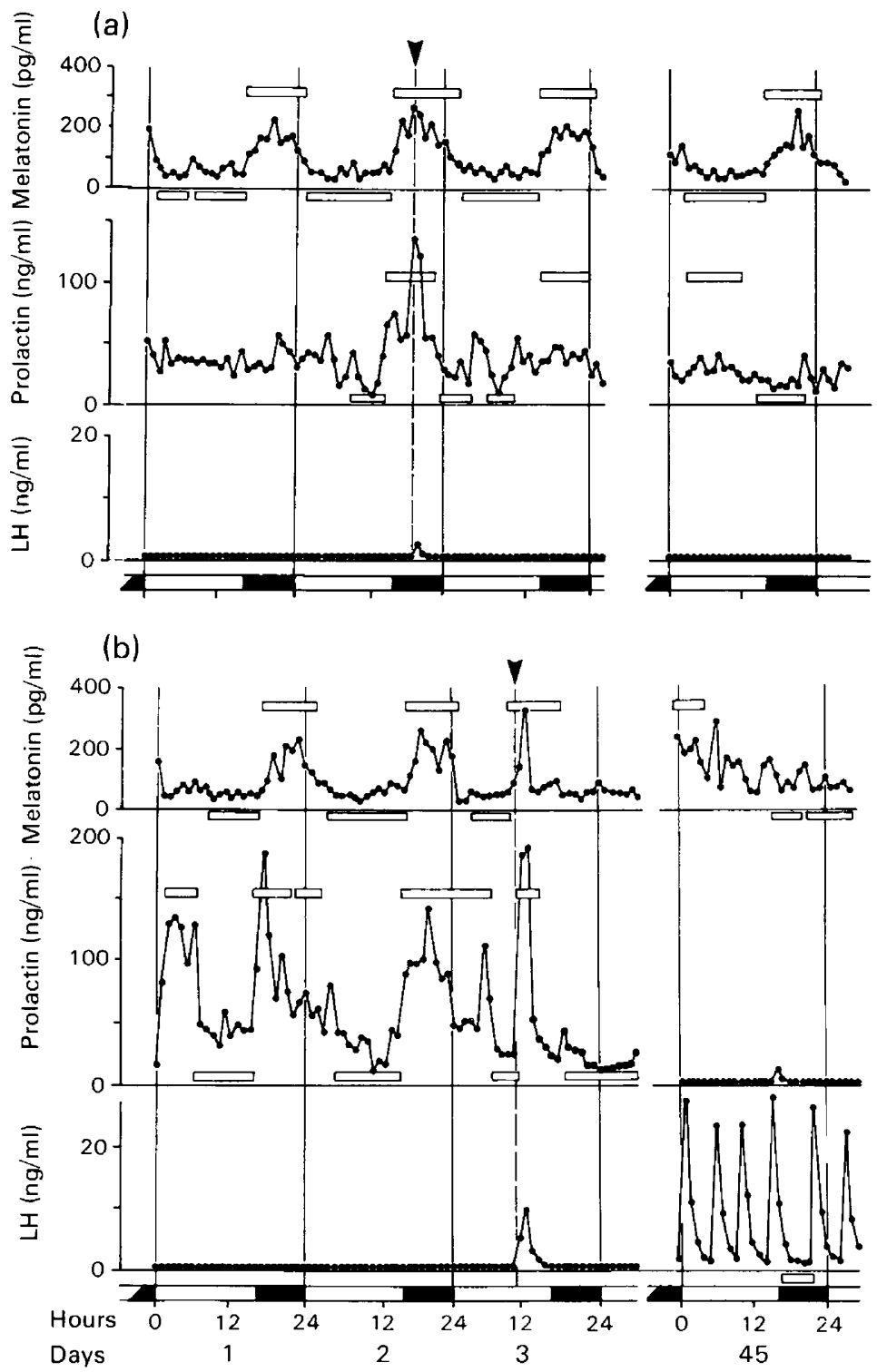

Text-fig. 3. Changes in the concentrations of melatonin, prolactin and LH in the blood plasma of (a) one control Soay ram that received a sham operation to expose the superior cervical ganglia, and (b) one ganglionectomized Soay ram. Blood samples were collected at hourly intervals of 3 days at the time of operation (arrow), and for one day 5 days later. The animals were exposed to long days (16L:8D) and the timing of the daily periods of daylight (open bar) and darkness (closed bar) is shown. The times when the hormone values were consistently high or low relative to the $24-\mathrm{h}$ median value are indicated by the open boxes in the panels.

1980; ferret: Herbert, 1981). Melatonin is one of the principal products of the pineal which is thought to influence the secretion of the anterior pituitary gland and affect reproduction (Wurtman \& Moskowitz, 1977; Turek \& Campbell, 1979; Reiter, 1980). In the sheep, there is a marked change in the circulating levels of melatonin from day to night and this daily pattern of secretion under long days is different from that under short days (Rollag et al., 1978; Lincoln \& 
Short, 1980; Arendt et al., 1980; Lincoln, Almeida, Klandorf \& Cunningham, 1982). The regulation of the pattern of melatonin secretion may thus be involved in the photoperiodic responses.

The results of the present study are consistent with this key role for melatonin. In particular, it was found that ganglionectomy caused an immediate disruption of the daily rhythm in the plasma levels of melatonin. After the operation there was no longer a consistent increase in the levels of melatonin associated with darkness. This change in the pattern of secretion of melatonin was correlated with the failure of the photoperiodic response; the long-day photoperiod was no longer effective in suppressing the plasma $\mathrm{LH}$ levels and increasing prolactin concentrations. The disruptive effect of ganglionectomy on melatonin rhythms and the reproductive responses has been described for Soay rams ganglionectomized for 3 years, indicating that the change is permanent (Lincoln et al., 1982). In this previous study the concentrations of melatonin in the plasma after ganglionectomy were intermediate between the daytime and night-time values found in control rams. The relatively higher levels of melatonin observed in the present study on Day 45 after ganglionectomy may reflect a hypersensitivity of the pineal gland that develops after removal of its sympathetic innervation; low levels of noradrenalin arriving in the peripheral blood may provide a stimulus for release (Wurtman \& Moskowitz, 1977).

Since ganglionectomy affected the pattern of secretion of melatonin, as well as the photoperiodic control of the secretion of LH and prolactin, it can be argued that photoperiod normally regulates the secretory activity of the anterior pituitary gland by dictating the daily rhythm in the release of melatonin. If melatonin is the specific hormone involved in this effect it should be possible to recreate the effects of long days on the secretion of LH and prolactin in ganglionectomized rams treated in the appropriate fashion with exogenous melatonin. There are extensive results from work on other seasonally breeding animals, including the golden hamster (Reiter, 1980), Djungarian hamster (Hoffman, 1981) and ferret (Herbert, 1981), which demonstrate that exogenous melatonin administered in different temporal patterns can simulate the effects of different photoperiods, and preliminary results with melatonin-treated rams also indicate the importance of this hormone (Lincoln \& Almeida, 1982).

\section{References}

Appleton, A.B. \& Waites, G.M.H. (1955) A surgical approach to the superior cervical ganglion and related structures in sheep. J. Physiol., Lond. 135, 52-57.

Arendt, J., Forbes, J.M., Brown, W.B. \& Marston, A. (1980) Effect of pinealectomy on immunoassayable melatonin in sheep. J. Endocr. 85, $1 P$, Abstr.

Barrell, G.K. \& Lapwood, K.R. (1979a) Effect of pinealectomy on the secretion of luteinizing hormone, testosterone and prolactin in rams exposed to various lighting regimens. J. Endocr. 80, 397-405.

Barrell, G.K. \& Lapwood, K.R. (1979b) Effects of various lighting regimens and pinealectomy on semen production in Romney rams. J. Reprod. Fert. 57, 273-284.

Corker, C.S. \& Davidson, D.W. (1978) The radioimmunoassay of testosterone in various biological fluids without chromatography. Steroid Biochem. 9, 373-374.

Herbert, J. (1981) The pineal gland and photoperiodic control of the ferrets' reproductive cycle. In Biological Clocks in Seasonal Reproductive Cycles, pp. 261-276. Eds B. K. Follett \& D. E. Follett. Wright, Bristol.
Hoffman, K. (1981) The role of the pineal gland in the photoperiodic control of seasonal cycles in hamsters. In Biological Clocks in Seasonal Reproductive Cycles, pp. 237-250. Eds B. K. Follett \& D. E. Follett. Wright, Bristol.

Kennaway, D.J., Porter, K.J. \& Seamark, R.F. (1978) Changes in plasma tryptophan and melatonin content in penned sheep. Aust. J. biol. Sci. 31, 49-60.

Lincoln, G.A. (1979) Photoperiodic control of seasonal breeding in the ram: participation of the cranial sympathetic nervous system. $J$. Endocr. 82, 135147.

Lincoln, G.A. \& Almeida, O.F.X. (1982) Melatonin and the seasonal photoperiodic response in sheep. In Photoperiodism and Reproduction in Vertebrates, pp. 231-251. Eds R. Ortavant, J. Pelletier \& J.P. Ravault. I.N.R.A., Versailles.

Lincoln, G.A. \& Short, R.V. (1980) Seasonal breeding: Nature's contraceptive. Recent Prog. Horm. Res. 36, $1-51$.

Lincoln, G.A., Almeida, O.F.X. \& Arendt, J. (1981) Role of melatonin and circadian rhythms in seasonal reproduction in rams. J. Reprod. Fert., Suppl. 30, 23-31. 
Lincoln, G.A., Almeida, O.F.X., Klandorf, H. \& Cunningham, R.A. (1982) Hourly fluctuations in the blood levels of melatonin, prolactin, luteinizing hormone, follicle-stimulating hormone, testosterone, tri-iodothyronine, thyroxine and cortisol in rams under artificial photoperiods, and the effects of cranial sympathectomy. J. Endocr. 92, 237-250.

MeNeilly, A.S. \& Andrews, P. (1974) Purification and characterization of caprine prolactin. $J$. Endocr. 60, 359-367.

Moore, R.Y. (1978) The innervation of the mammalian pineal gland. In The Pineal and Reproduction, pp. 1-29. Ed. R. J. Reiter. S. Karger, New York.

Pelletier, R. \& Ortavant, R. (1975) Photoperiodic control of $\mathrm{LH}$ release in the ram. Influence of increasing and decreasing light photoperiods. Acta endocr., Copenh. $78,435-441$.

Reiter, R.J. (1980) The pineal and its hormones in the control of reproduction in mammals. Endocrine Reviews, 1, 109-131.

Rollag, M.D. \& Niswender, G.D. (1976) Radioimmunoassay of serum concentrations of melatonin in sheep exposed to different lighting regimens. Endocrinology 98, 482-489.

Rollag, M.D., O'Callaghan, P.L. \& Niswender, G.D. (1978) Serum melatonin concentrations during different stages of the annual reproductive cycle in ewes. Biol. Reprod. 18, 279-285.

Scaramuzzi, R.J., Caldwell, B.V. \& Moor, R.M. (1970) Radioimmunoassay and oestrogen during the estrous cycle in the ewe. Biol. Reprod. 3, 110-119.

Sharp, D.C., Vernon, M.W. \& Zavy, M.T. (1979) Alteration of seasonal reproductive patterns in mares following superior cervical ganglionectomy. $J$. Reprod. Fert., Suppl. 27, 87-93.

Turek, F.W. \& Campbell, C.S. (1979) Photoperiodic regulation of neuroendocrine gonadal activity. Biol. Reprod. 20, 32-50.

Wurtman, R.J. \& Moskowitz, M.A. (1977) The pineal organ. New Eng. J. Med. 296, 1329-1333; 13831386. 